\title{
INCREASING INFORMATION FEED IN THE PROCESS OF STRUCTURAL STEEL DESIGN
}

\author{
P. Pauwels ${ }^{1}$, T. Jonckheere ${ }^{1}$, R. De Meyer ${ }^{1}$ and J. Van Campenhout ${ }^{2}$ \\ ${ }^{1}$ Department of Architecture and Urban Planning, Ghent University, Belgium \\ ${ }^{2}$ Department of Electronics and Information Systems, Ghent University, Belgium
}

\begin{abstract}
Research initiatives throughout history have shown how a designer typically makes associations and references to a vast amount of knowledge based on experiences to make decisions. With the increasing usage of information systems in our everyday lives, one might imagine an information system that provides designers access to the 'architectural memories' of other architectural designers during the design process, in addition to their own physical architectural memory. In this paper, we discuss how the increased adoption of semantic web technologies might advance this idea. We investigate to what extent information can be described with these technologies in the context of structural steel design. This investigation indicates possibilities regarding information reuse in the process of structural steel design and, by extent, in other design contexts as well.
\end{abstract}

Keywords architectural design, information, reasoning, semantic web

\section{INTRODUCTION}

Research initiatives throughout history have shown how a designer typically makes associations and references to a vast amount of knowledge based on experiences to make decisions. In the case of architectural design, this 'architectural memory' includes not only real life experiences, but also experiences stemming from literature, images, movies, active discussions, etc. Any experience that is somehow related to architectural design, shapes the designer's architectural memory, which in turn shapes the designer's decisions. With the increasing usage of information systems in our everyday lives, one might imagine an information system that provides designers access to the architectural memories of other architectural designers during the design process, in addition to their own physical architectural memory.

The increased adoption of semantic web technologies might advance this idea. These technologies namely promise the means to connect all kinds of different information into one semantic web, so that it is understandable, or at least reusable by computer agents. We investigate to what extent information can be described with these technologies in the context of structural steel design. As the result includes explicit connections to information available in the global semantic web, we aim at giving an idea of what kind of information can be made available easily and to what limits the information feed in the design process can hence be increased. This investigation indicates possibilities regarding global information reuse in a design context.

\section{DESIGN THINKING}

A significant amount of research has already been spent on the nature of design thinking, in all of its flavours, as this is commonly considered one of the most peculiar activities of the human mind. Through a very complex process of design thinking, designers are able to bring about the most innovative and surprising solutions to the most troublesome situations. Research in this area has boomed with the advent of computers into our world. The remarkable reasoning and computing power of a computer made one imagine how computers could support the design process and, if possible, to what extent. However, before one can build a computer supporting a designer in his or her design thinking, one first needs to understand how a designer thinks, regardless of the context of the design (e.g. automotive, architecture, etc.).

\subsection{How designers think}

It is hardly possible to give an adequate overview of research on the topic 'how designers think'. We therefore refer to several already existing historical overviews to get an idea of evolutions in design thinking research $[1,2,3]$. These overviews document the overall movements and most significant approaches and viewpoints in research on design thinking from the 1960s until now. Research in this domain resulted in a long-standing design research tradition that focuses on the importance of context and the specific kind of action and interaction with the situation at hand and with existing knowledge. Major theories in this regard 
are those coined by Nigel Cross [3-9], Bryan Lawson [10,11], Donald Schön [12], Herbert Simon [13], and Christopher Alexander [14-18].

As is pointed out in these theories, design thinking relies heavily on a reflective, 'learning-while-doing' character. A designer continuously forms theories on his or her design and on design in general while interacting with it. By actively experiencing design, a designer forms a renewed understanding of design in general, which may include his or her own design and which may subsequently effect in important changes on the design at hand. This understanding is found to be the main driver behind design decisions and design alternatives: designers rely on previously experienced design decisions to make new design decisions. Over the years, the design research community has pointed out how this latter kind of reasoning is critical to any creative thought of the human mind. This kind of reasoning is called 'abductive reasoning' $[5,6]$ and references are made to the work of Charles Sanders Peirce [19]. This occurs most often in combination with deductive and inductive reasoning, as it is also discussed in [20-25], and as part of a process of 'scientific enquiry' [19].

A good description of this process of 'scientific enquiry' is given by Flach \& Kakas in [24]: "When confronted with a number of observations she seeks to explain, the scientist comes up with an initial hypothesis; then she investigates what other consequences this theory, were it true, would have; and finally she evaluates the extent to which these predicted consequences agree with reality. Peirce calls the first stage, coming up with a hypothesis to explain the initial observations, abduction; predictions are derived from a suggested hypothesis by deduction; and the credibility of that hypothesis is estimated through its predictions by induction." (Figure 1).

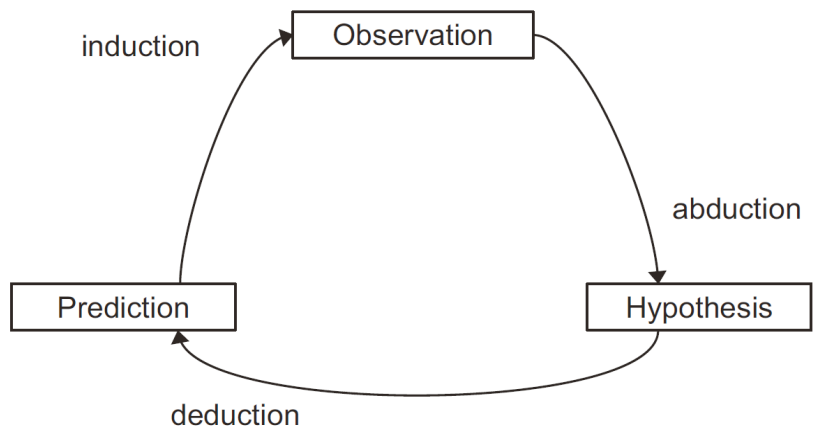

Figure 1. The process of 'scientific enquiry' as outlined by C.S. Peirce [19], indicating how the three reasoning modes, i.e. abduction, induction and deduction, function as a whole, underlying human thought.

The reasoning cycle of abduction-deduction-induction (Figure 1) is most often explained from an observational point of view. The main questions that are supposedly handled in such an observational reasoning cycle are: what do we observe, what would be a good explanation for our observation, and what will we observe next? More scarce are the discussions of how this reasoning cycle is at play in a design context. A good recent overview in this regard can nonetheless be found in the work of Edwin Gardner [26] and in our overview paper [27], which illustrates how a designer relies on all three thinking modes during design thinking, thereby referring to appropriate examples in architectural design contexts.

In [27], we documented this reasoning cycle in the context of design thinking as follows: "When a designer 'synthesises the facts', for instance by preliminary sketches or physical models, he or she essentially creates an alternative observation of the same situation, which leads instinctively to abductive reasoning lines and thus to hypotheses about the design situation at hand [(see 'abduction' in Figure 1)]. The 'continuous examples that come to mind from the architect's repertoire' indicate the importance of personal experiences of the designer in this abductive process. If a designer underwent 20 years of positive experiences with a grid layout to organise design situations, this has become a very strong and trustworthy rule within this designer's understanding of 'good architecture', and a higher probability value will consequently be attributed when making this hypothesis. By incorporating a hypothesis in a design, a designer consciously or unconsciously adds a whole set of rules to a design, rules that were attributed inductively to the added concepts throughout all kinds of personal experiences with this concept. By 'plugging in' these personal understandings or rule sets in a design, implications or predictions can be deduced [(see 'deduction' in Figure 1)]. Based on these predictions, experiments are set up and gone through in each reasoning cycle, using a specific representation model. For instance, a designer may choose to just imagine the consequences of his or her hypothesis, he or she might actually make a sketch of the situation, or possibly build a detailed 3D representation. Whatever the designer chooses as a representation model, he or she will always make an observation of this experiment and make some conclusions inductively [(see 'induction' in Figure 1)]. Most often, this observation in itself is the starting point of a new reasoning cycle, making it seem as if the design situation in itself steers the design thinking 
process one way or another. In other words, the designer learns while doing, he or she is in a reflective conversation with the situation [12]."

What we are interested in in our research, is what parts of this reasoning cycle are already actively supported by information systems, how this support might be improved, and what other parts might be supported additionally. For instance, one can easily see how 3D modelling technologies provide support for the inductive reasoning phase. By enabling a designer to model a building in a 3D model, the software allows him or her to set up a virtual experiment, which can then be observed and serve as a start for a whole range of new reasoning cycles. Similarly, calculation and simulation software clearly provides support for the deductive reasoning phase of the design process, by making calculations and simulations based on a limited set of premises. What appears to be far less obvious, is the support for abductive reasoning lines in the design process. Activities supported by or resulting from this reasoning mode are typically considered first and foremost creative by nature and are hence immediately considered as taboo for anything non-human. Significant attempts can nonetheless be named in support of this reasoning phase, which is the main subject for the remainder of this paper.

\subsection{Traditional information system support for abductive reasoning in a design context}

In order to understand how one may support abductive thinking in a human mind, one needs a thorough understanding of this kind of reasoning. The most important element for this kind of reasoning, is its starting point: an ever increasing set of 'experiences' stored in the human mind. Based on this set of experiences, a designer makes hypotheses which are possibly 'wrong', but which lie nonetheless at the basis of further decision-making $[19,26,27]$. This has consequently been the focus of several research initiatives in the context of architectural design: improve / enlarge the set of experiences of a designer through information and communication technology (ICT). By feeding the 'right' type of information into a designer's mind at the right time, a supposedly better or 'more right' design will result.

One of the most direct approaches to bring all kinds of architectural information into a digital design environment, is to implement a huge knowledge base containing this information and connect it with one or more of the available digital design environments. Many such knowledge bases can be named in the context of architectural design, in all kinds of flavours and sizes.

Digital object repositories, or digital archives, function similar to regular archives. All kinds of information is labelled and added to the archive, after which this information becomes 'available' to all through its labels. The information available in these archives can typically be split up as 'data' and 'metadata', the former being the information to be stored, and the latter being the labels that can be used to retrieve this information. A good example of such a digital repository can be found in the aDORe framework, which was deployed in the Los Alamos National Library and in the Ghent University Library [28-32]. Examples of such repositories in the context of design, and more specifically of architectural design, are DYNAMO [44], Building Stories[45-50], Europeana [51] and MACE [52].

The Dynamic Architectural Memory On-line (DYNAMO) is a knowledge base designed and implemented at the Department of Architecture at the KULeuven [44]. Similar representative university repositories for architectural information are the Ariadne Knowledge Pool System (KPS) [34-37], the WINDS Web Based Intelligent Design Tutoring System [38-40], and the International Construction Database (ICONDA) of the International Council for Building Research, Studies and Documentation (CIB) [41]. The original aim of the DYNAMO repository was to "provide a platform for interaction and knowledge exchange between designs and (student-)designers in various contexts and at different levels of experience." (Heylighen in [42]). This includes interaction between designs, between human designer and computer, between (student) designers, and between practice and education [42, 43]. These kinds of interaction are made possible by collecting all kinds of architectural design 'cases' and interconnecting them in a labelled web-like structure "that allows retrieving and browsing between design cases in multiple ways. Every project is labelled with several features and linked to projects with common characteristics. If we consider design cases as encapsulations of design knowledge, this web of indices further enhances each case's value. It allows students to approach a design from different perspectives and to situate it in relation to other designs. The knowledge content of DYNAMO therefore does not only reside in the cases it contains, but also in the web of indices between them." (Heylighen and Neuckermans in [44]). In the end, DYNAMO was implemented as an SQL database accessible through a graphical user interface in a web browser for online browsing and searching. During the evaluation process, DYNAMO came out as an inspiring addition to the already available information, but important barriers were found regarding privacy and intellectual property [43].

A remarkable alternative approach is the one adopted in the Building Stories project [45-50]. This research project starts from the hypothesis that design typically relies on tacit, experience-based knowledge, which is often communicated effectively through story telling. Instead of constructing a repository of digital objects labelled using a repository-specific or standard metadata schema, as is more or less the case in DYNAMO, WINDS, Ariadne and ICONDA, the Building Stories project aims at building a repository of stories. 
Researchers then further focused on how to make the most appropriate stories available depending on the design situation, which is in this case reflected by a search query to the database [47]. This is accomplished by labelling the stories with metadata based on their contents and graphically matching the queried situation and the stories in the database [46].

Over recent years, these initial initiatives are brought on a wider scale through several European projects, including 'Metadata for Architectural Contents in Europe' (MACE) and Europeana. MACE represents an European initiative towards an on-line knowledge base for architecture [33]. An online portal merges several of the previously existing architectural repositories into one metadata schema for online browsing and querying of architectural contents [51]. Europeana is a similar European project, focusing alternatively on European culture and scientific heritage [52]. The main contribution of these initiatives is the availability of huge amounts of resources through one portal. Essentially, they provide designers the means to browse through history and learn from resources from the past.

\subsection{So, what support is now available for the abductive reasoning of a designer?}

When looking a little closer at the initial goals and the now available results of the briefly outlined research projects, at least one important remark should be made. Namely, in many cases the research projects intended to provide architectural designers with information from previous experiences by others. By making a labelled repository of images, texts, 3D models, etc., however, they essentially enable designers to make additional experiences, and not to find information that others acquired through their experiences. There is a subtle but very important difference between those two, and both imply very different expectancies regarding software usage.

In the latter case, one typically expects architectural designers to log in to a huge shared database of information resulting from the experiences of others, search for and find specific information (e.g. details on the curvature of a beam supported at the ends with a span of $2 \mathrm{~m}$ ), and just 'absorb' of 'embrace' exactly this information as if it were his or her own experience. This does not happen, however. As is more or less clear from the research projects above, one can easily make annotations of how certain objects are experienced or interpreted by others, but when a designer retrieves information, he or she will merely make a new observation in his or her own mind and does not incorporate the information acquired by others through previous experiences.

This appears in agreement with the workings of the abductive - deductive - inductive reasoning cycle briefly documented above. One always starts from a very specific observation, whether this comes from reality (e.g. standing in a building, sketching, 3D modelling) or imagination (e.g. reading a book, making conversation, thinking, etc.). This triggers the abductive reasoning process, eventually resulting in a new observation or experience. By seeing a structural design described on the web, one thus does not incorporate this design information as new information, but instead considers this a completely new observation, a new start point for a new reasoning cycle, possibly resulting in very different information than originally described in the knowledge base.

So, what if this is an equally valid goal? Is the goal 'support for the abductive reasoning of a designer' not accomplished by providing a designer the ability to enter keyword(s), find something possibly relevant and making new experiences that help him or her make a certain design decision? Yes, because the knowledge of the designer is enlarged through the extra experience, which might help in his or her decision making. One must nonetheless acknowledge the limits of this kind of support, as it appears almost irrelevant what information is provided to the designer, considering that he or she is building his or her own interpretation from it anyway.

A similar scenario is at play for the way in which architects build up and rely upon their 'architectural memory' in a world without computer support. Any architect merely experiences the world by chance. If Le Corbusier would not have received some very specific experiences as a child, he probably would not have decided to go to the School for Decorative Arts in Switzerland. If he would not have received some very specific experiences in the School for Decorative Arts in Switzerland, he would probably not have gone to study with Hoffmann nor Perret. If he would not have received some very specific experiences in his time of study with Hoffman and Perret, he probably would not have become the famous architect he became. Etc. etc. By simply replacing one of his experiences, Le Corbusier would have made different decisions and become somebody else by mere chance. Analogously, providing lots and lots of information in an online knowledge base to a human designer will not necessarily make this person a better designer, nor will it enable him or her to make better decisions. It will just make him or her a different person, shape his or her future decisions similar to how any other experience might shape someone's future decisions. Support for the abductive reasoning part (the creative thinking part) of a designer can only be useful in this sense. 


\section{EXTENDING BOUNDARIES USING SEMANTIC WEB TECHNOLOGIES}

Considering the objective outlined above, previously documented information systems for abductive reasoning support do show a considerable usefulness. They enable one to make new observations or experiences through a simple query. Simply by browsing through the various resources available in MACE and in Europeana, one enlarges his or her set of experiences and consequently shapes how he or she makes decisions.

A technology that may further improve this approach, can be found in the semantic web domain. This domain has evolved from research in the context of the World Wide Web (WWW), in which information is described so that it "will open up the knowledge and workings of humankind to meaningful analysis by software agents, providing a new class of tools by which we can live, work and learn together." (BernersLee in [53]). By describing all information in one giant semantic web graph, a linked open data (LOD) cloud, a graph structure, or whatever name you might prefer, in principle it would become possible for people to describe each of their experiences in detail and link them together into one global semantic web graph. Digital agents would be able to search through this graph, or any part of the graph you prefer, and find you the most relevant information. The main difference with providing information in separate closed repositories, similar to how it is done in the previously documented examples, is that (1) any information in any (metadata) schema might become available, thus considerably enlarging the knowledge base, and (2) experiences might be described far more densely than is currently the case when following merely one metadata schema, thus allowing considerably more specific search queries. By such a vertical and horizontal enlargement of the available knowledge base, one is able to fine-tune the way in which he or she undergoes experiences and makes observations. This does not imply a better or a more efficient decisionmaking, because the decisions made will remain as fallible as they ever were. It will only allow people to choose more precisely what they want to experience, similar to how certain architects are more able to choose which buildings, countries, people, etc. they want to visit.

We have already discussed the usage of semantic web technologies for the description of architectural information in [54-56]. This described how we have built a web of semantic Architectural Information Modelling (AIM) information to simulate how information might be available when relying on semantic web technologies. This research has started with expressing building information in a semantic web format, namely the Resource Description Language (RDF) [57], which essentially represents information in a directed, labelled graph. In Figure 2, an example of such a labelled graph is shown, illustrating how one may describe a steel construction as an aggregation of columns and beams.

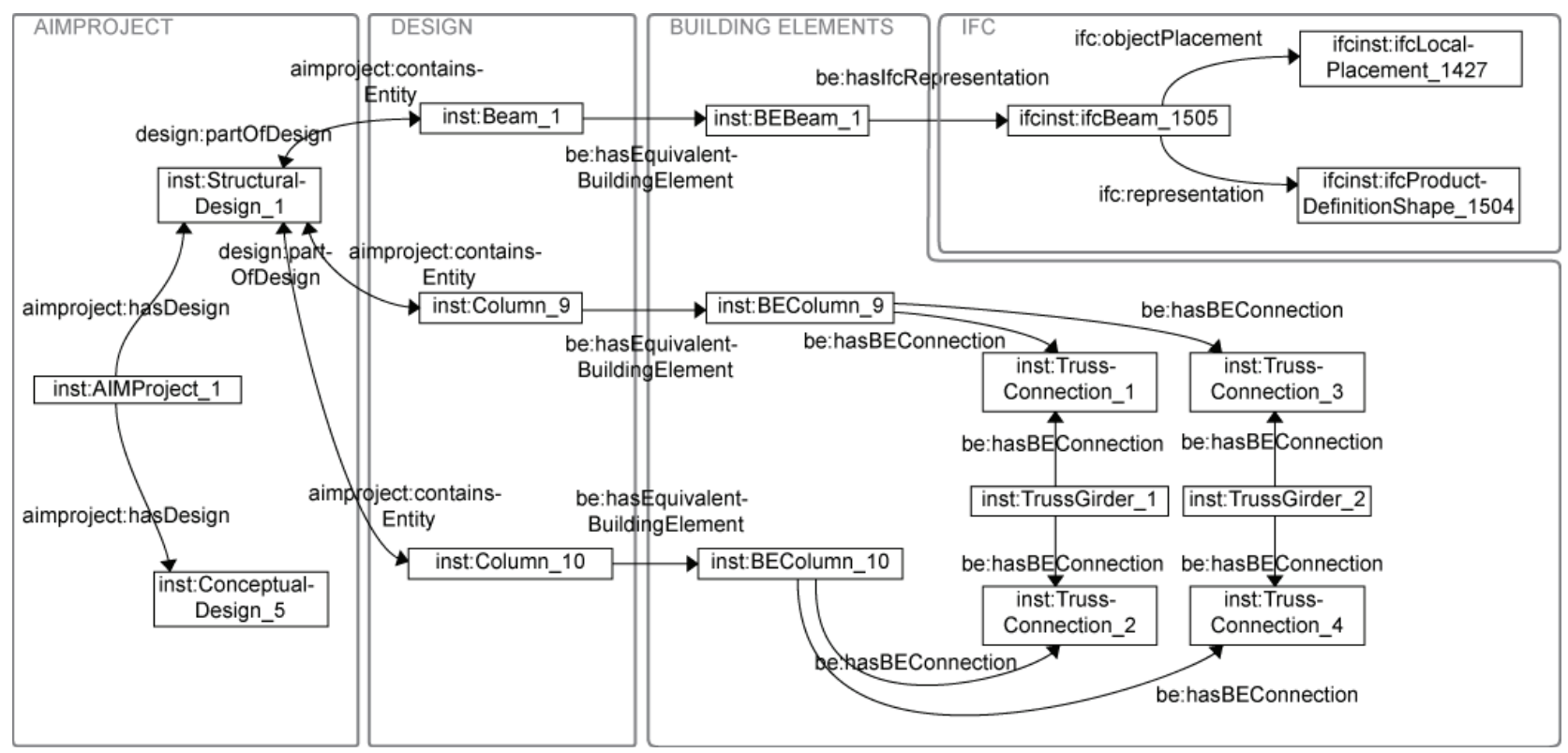

Figure 2. Part of an RDF graph illustrating how a steel construction may be described as an aggregation of columns and beams [56].

Of significant importance is the possibility to further link this information to any kind of information similarly described using semantic web technologies. Information that is not considered a direct part of a certain subdomain, can thus be connected to a graph describing this subdomain and hence be made available as well. This has resulted in what appears to become the largest data source available online, namely the Linked Open Data (LOD) cloud (Figure 3), which currently contains over 25 billion facts [58,59]. By actively describing architectural information in a semantic web format (Figure 2) and connecting parts of it to this LOD cloud, we target a more specific description of information, both in a vertical (more in-depth detail) and 
a horizontal (broader descriptions) sense, thereby further improving the support for abductive reasoning processes in an architectural design context. We will discuss this briefly in the context of structural steel design.

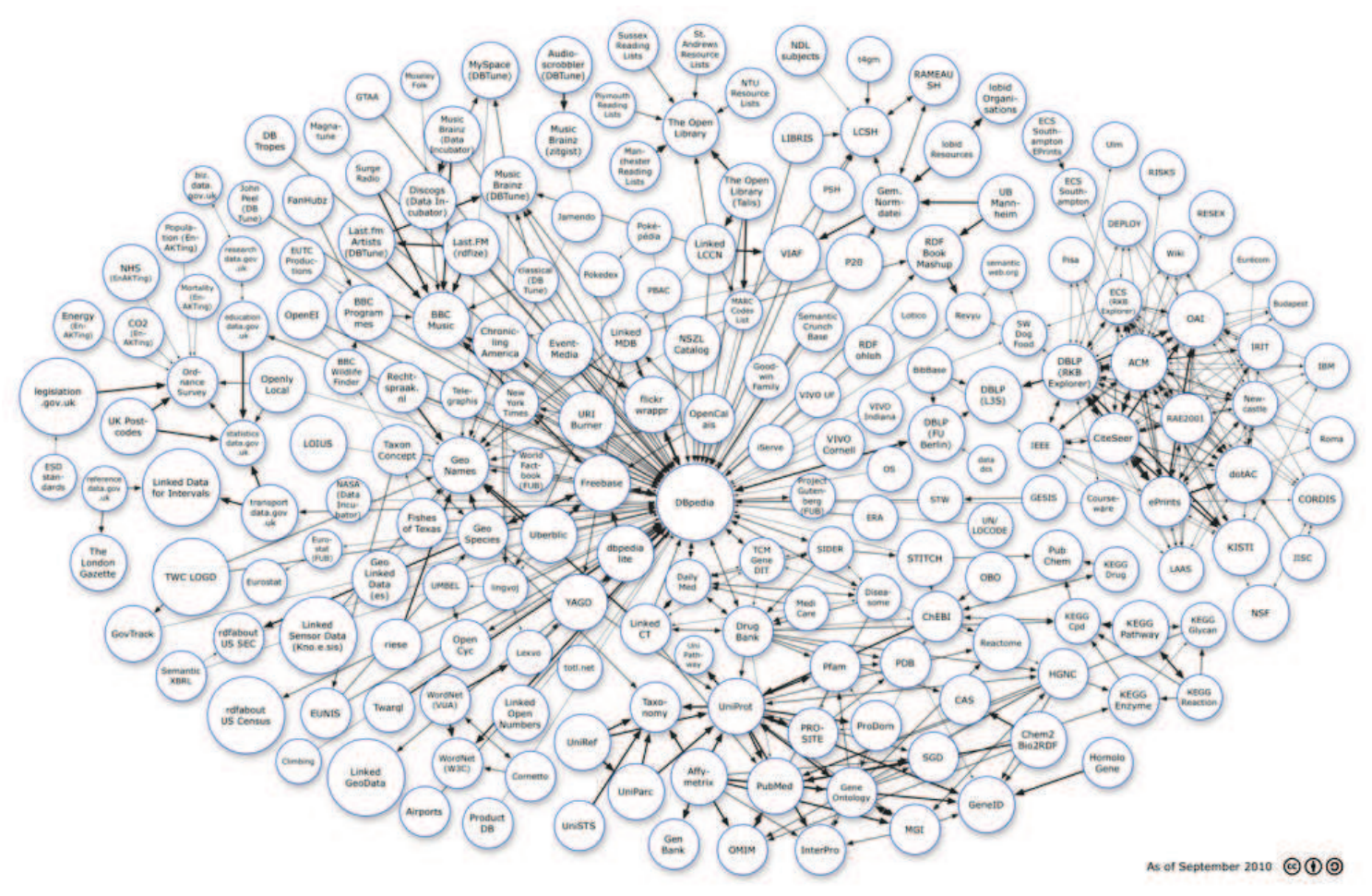

Figure 3. The LOD cloud on 2010-09-22 (original image on [59]).

\section{THE CASE OF STRUCTURAL STEEL DESIGN}

An example RDF graph was built for a structural steel design in Antwerp, Belgium (Figure 4). A small part of this graph was already given in Figure 2. Largely following an in-house structure of AIM ontologies [56], the complete graph explicitly links design properties to construction type properties, geometric properties, material properties, 3D placement properties, etc. So far, this has resulted in a graph structure of about 100.000 RDF statements.

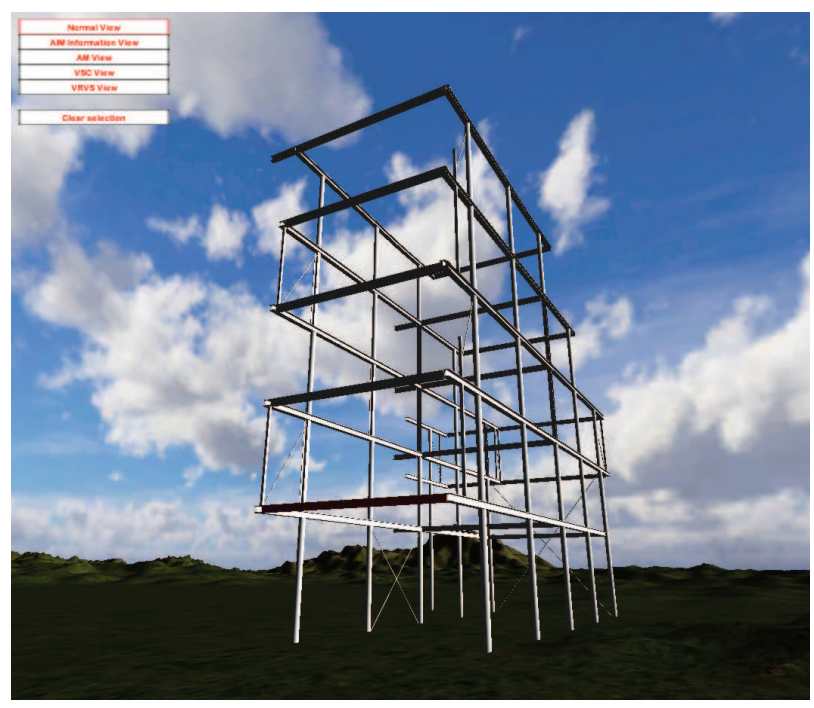

Figure 4: Building information model visualised in a virtual environment.

What is important here, is that this graph, or parts of this graph, can easily be connected to information that may not be considered a direct part of the AEC domain in which this building model was modelled, but that one may nonetheless want to use to find this building model in an application supporting the abductive reasoning processes of a designer. This may include for instance geographical information, people and organisation information or expert material information. By linking this building model to this kind of information, one can use parameters in these fields as well, consequently actively narrowing his or her 
search down to what he or she wants. This allows one, for instance, to search for building models related to very specific photographs, related to very specific types of material, in a specific location, or related to a certain designer, which is not possible when relying solely on the information originally available in the building model. In our experimental case concerning the structural steel design in Antwerp, we tested the connection of the building model to the following resources available in the LOD cloud.

\subsection{Linking to geographical information}

The GeoNames geographical database [60] provides access to information about all countries and 8 million place names. Information is available in various languages, covering characteristics such as latitude longitude coordinate pairs, capital names, highest mountains, population statistics, postal codes, country codes, statistics on specific features (parks, military bases, waterfalls, etc.), etc. There is no need to describe all this information in a building model. Instead, one only needs to link the RDF graph of the building model to the element of relevance to make this information available (Figure 4).

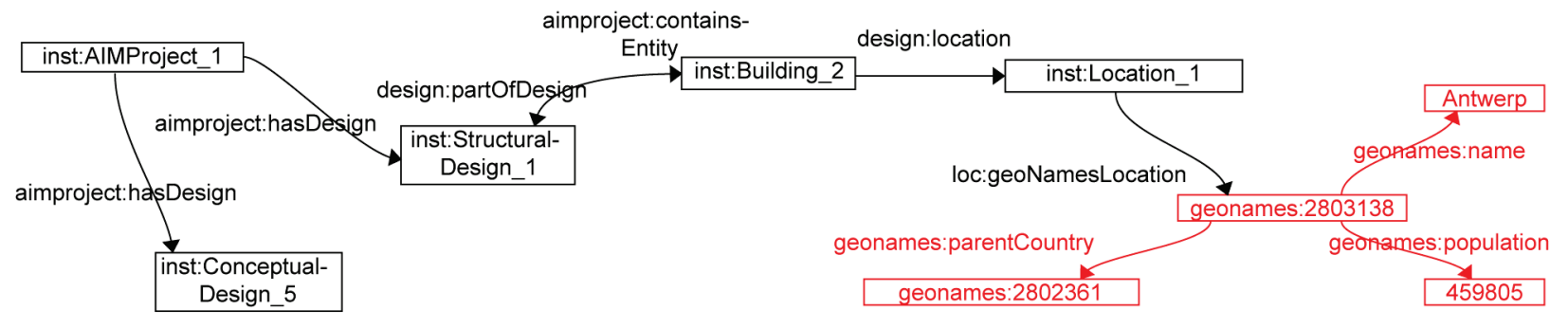

Figure 5. Linking a building model to a specific location in the GeoNames database (in red) [60].

\subsection{Linking to expert material information}

Research by Zhang et al. [61] has targeted the conversion of MATML information into a MatOWL information, in order to make material data more easily accessible to material scientists, namely through semantic queries. Although this research originally focuses on material scientists, added value may be within reach also for AEC specialists when they have the means to connect certain building products to concrete expert material information and hence make this expert information available for calculations and simulations, including for instance a structural calculation of a steel structure.

\subsection{Linking to people and organisation information}

The Friend of a Friend (FOAF) project has resulted in a machine-readable ontology allowing the description of people and organisations, including their main activities and main relations to other people and organisations [62]. Using this ontology, one can describe this kind of information and subsequently link this information to other relevant information. In this case, the various actors in the AEC project were described in this FOAF ontology and appropriately linked to the structural steel design project.

\subsection{Linking to photo material}

Currently, flickr is one of the world's largest online photo archives. Recently, a 'flickr wrapper' has been developed as part of the efforts in the semantic web domain to convert existing unstructured information into its structured equivalent [63]. This effort focuses on linking photo collections to articles on DBpedia, which is the largest semantic web archive currently available providing the user with a collection of structured data extracted from the Wikipedia website [64]. Thanks to the flickr wrapper, articles on DBpedia, for instance on the Brandenburg Gate in Berlin, can have a 'dbpedia:hasPhotoCollection' property, linking the article in question to a specific photo collection in the flickr repository. Considering the information already available in our RDF graph for the structural steel design in Antwerp, one can easily imagine several links to DBpedia resources, e.g. for the location and for the people and organisations involved, hence also making available several photo collections that might be relevant for applications providing support for abductive reasoning processes in architecture.

\section{CONCLUSIONS}

A lot of research has already focused on design thinking and the processes underlying this thinking. In this paper we have taken a closer look at one of the most creative of these processes, namely abductive reasoning. Relying on this specific kind of reasoning, a designer is thought to generate the hypotheses that may in further design phases evolve into the core elements of a design idea. We have outlined in this paper how essential the incoming information feed is for this kind of reasoning. Starting from the continuously incoming stream of information, a designer makes the decisions he or she thinks are best. 
We have outlined in this paper how ICT support for this reasoning process typically targets an improvement in the information flow towards the designer. Software designers and developers aim at providing the designer with the information he or she needs most. We have discussed why one may want to rely on a slightly different objective, and not focus on providing information he or she needs most, but instead on providing the best search circumstances possible. There exists no 'information needed most', there only exists 'information', and one can only provide the best means to access and search through this information as efficiently as possible, finding as fast as possible what one really wants to find.

We have discussed why the reliance on semantic web technologies might improve search circumstances or search functionality compared to existing approaches in the AEC domain, because this technology enables one to enlarge information sources both in a vertical and in a horizontal sense. We have briefly indicated how this enlargement can take place in the context of a structural steel design in Antwerp.

\section{ACKNOWLEDGEMENTS}

This research is a part of research at the UGent SmartLab research groups, supported by both the Department of Electronics and Information Systems and the Department of Architecture and Urban Planning of Ghent University. The authors gratefully acknowledge the funding support from the Research Foundation - Flanders (FWO) and UGent BOF.

\section{REFERENCES}

[1] Bayazit, N., Investigating design: a review of forty years of design research, Design Issues 20(1), 1629, 2004.

[2] Cross, N., Design Research Now, In: From a Design Science to a Design Discipline: Understanding Designerly Ways of Knowing and Thinking (pp. 41-54), Basel: Birkhauser, 2007.

[3] Cross, N., Forty years of design research, Design Studies 28(1), 1-4, 2007.

[4] Cross, N., Designerly ways of knowing, Design Studies 3(4), 221-227, 1982.

[5] Cross, N., Styles of learning, designing and computing, Design Studies 6(3), 157-162, 1985.

[6] Cross, N., The nature and nurture of design ability, Design Studies 11(3), 127-140, 1990.

[7] Cross, N., Descriptive models of creative design: application to an example, Design Studies 18(4), 427455, 1997.

[8] Cross, N., Natural intelligence in design, Design Studies 20(1), 25-39, 1999.

[9] Cross, N., Designerly ways of knowing, London: Springer Verlag, 2006.

[10] Lawson, B., Cognitive strategies in architectural design, Ergonomics 22(1), 59-68, 1979.

[11]Lawson, B., How Designers Think - The Design Process Demystified, Oxford: Architectural Press, 4th edition, 2005.

[12] Schön, D., The Reflective Practitioner: How Professionals Think in Action, London: Temple Smith, 1983.

[13] Simon, H., The Sciences of the Artificial, Cambridge: MIT Press, 3rd edition, 1996.

[14] Alexander, C., Notes on the Synthesis of Form, Cambridge: Harvard University Press, 1964.

[15]Alexander, C., The State of the Art in Design Methods, Design Methods Group Newsletter 5(3), 3-7, 1971.

[16] Alexander, C., Ishikawa, S., Silverstein, M., A Pattern Language: Towns, Buildings, Construction, New York: Oxford University Press, 1977.

[17]Alexander, C., The Timeless Way of Building, New York: Oxford University Press, 1979.

[18] Alexander, C., The Nature of Order: An Essay on the Art of Building and the Nature of the Universe, Berkeley: CES publishing, 2004.

[19] Peirce, C.S., Collected Papers of Charles Sanders Peirce, vols. 1-6 (Eds. C. Hartshorne \& P. Weiss) (1931-1935), vols. 7-8 (Ed. A.W. Burks) (1958), Cambridge: Harvard University Press, 1958.

[20]Aliseda-LLera, A., Seeking Explanations: Abduction in Logic Philosophy of Science and Artificial Intelligence, PhD Dissertation, University of Amsterdam, The Netherlands, 1997.

[21] Ray, O., Hybrid Abductive Inductive Learning, PhD Dissertation, University of London, UK, 2005. 
[22] Paavola, S., On the Origin of Ideas: An Abductivist Approach to Discovery, PhD Dissertation, University of Helsinki, Finland, 2006.

[23] Fischer, H.R., Abductive Reasoning as a Way of Worldmaking, Foundations of Science 6(4), 361-383, 2001.

[24]Flach, P.A., Kakas, A.C., Abductive and inductive reasoning: background and issues, In: (Eds. P.A. Flach \& A.C. Kakas) Abduction and Induction: Essays on their Relation and Integration (pp. 1-27), Dordrecht: Kluwer Academic Press, 2000.

[25] Queiroz, J., Merrell, F., Abduction: Between subjectivity and objectivity, Semiotica 153(1/4), 1-7, 2005.

[26] Gardner, E., Reasoning in Architecture - About the Diagrammatic Nature of Thinking with Real and Imagined Objects, Master thesis, Delft University of Technology, The Netherlands, 2009.

[27]Pauwels, P., De Meyer, R., Van Campenhout, J., The role of reasoning in human design thinking. Design Studies, 2011 (submitted).

[28] Bekaert, J., Standards-based interfaces for harvesting and obtaining assets from digital repositories, PhD Dissertation, Ghent University, Belgium, 2006.

[29] Bekaert, J., Hochstenbach, P., Van de Sompel, H., Using MPEG-21 DIDL to represent complex digital objects in the Los Alamos National Laboratory Digital Library, D-Lib Magazine 9(11), 2003.

[30] Bekaert, J., Balakireva, L., Hochstenbach, P., Van de Sompel, H., Using MPEG-21 DIP and NISO OpenURL for the dynamic dissemination of complex digital objects in the Los Alamos National Laboratory Digital Library, D-Lib Magazine 10(2), 2004.

[31] Van de Sompel, H., Bekaert, J., Liu, X., Balakireva, L., Schwander, T., aDORe: A Modular, StandardsBased Digital Object Repository, The Computer Journal 48(5) 514-535, 2005.

[32] Van de Sompel, H., Chute, R., Hochstenbach, P., The aDORe federation architecture: digital repositories at scale, International Journal on Digital Libraries 9(2) 83-100, 2008.

[33] Neuckermans, H., Wolpers, M., Heylighen, A., Data and metadata in architectural repositories. In: Proceedings of the 12th International Conference on Computer-Aided Architectural Design Research in Asia, 489-497, 2007.

[34]Duval, E., An open infrastructure for learning - the ARIADNE project: share and reuse without boundaries, In: Proceedings of ENABLE99: Enabling Network-Based Learning, 144-151, 1999.

[35] Duval, E., Forte, E., Cardinaels, K., Verhoeven, B., Van Durm, R., Hendrikx, K., Forte, M.W., Ebel, N., Macowicz, M., Warkentyne, K., Haenni, F., The ARIADNE Knowledge Pool System: a Distributed Digital Library for Education, Communications of the ACM 44(5), 73-78, 2001.

[36] Najjar, J., Ternier, S., Duval, E., The actual use of metadata in Ariadne: an empirical analysis, In: Proceedings of the 3rd annual Ariadne conference 1-6, 2003.

[37]Ternier, S., Olmedilla, D., Duval, E., Peer-to-peer versus federated search: towards more interoperable learning object repositories, In: (Eds. P. Kommers \& G. Richards) Proceedings of the World Conference on Educational Multimedia, Hypermedia and Telecommunications 1421- 1428, 2005.

[38] Kravcik, M., Specht, M., Flexible navigation support in the WINDS learning environment for architecture and design, In: (Eds. P.D. Bra \& W. Nejdl) Proceedings of the 3rd International Conference on Adaptive Hypermedia and Adaptive Web-Based Systems 156-165, 2004.

[39] Kravcik, M., Specht, M., Oppermann, R., Evaluation of WINDS Authoring Environment, In: (Eds. P.D. Bra \& W. Nejdl) Proceedings of the 3rd International Conference on Adaptive Hypermedia and Adaptive Web-Based Systems 166-175, 2004.

[40] Kravcik, M., Specht, M., Experience with WINDS virtual university, In: (Eds. P. Kommers \& G. Richards) Proceedings of the World Conference on Educational Multimedia, Hypermedia and Telecommunications 642-649, 2005.

[41]Fraunhofer IRB, ICONDA Bibliographic - Find and Access Publications on Planning and Building, http://www.irb.fraunhofer.de/iconda/ (last accessed on 3rd January 2011).

[42] Heylighen, A., In case of architectural design - Critique and praise of Case-Based Design in architecture, PhD Dissertation, KULeuven, 2000.

[43] Heylighen, A., Neuckermans, H., Casaer, M., ICT revisited - From information \& communication to integrating curricula?, Journal of Information Technology in Construction 9, 101-120, 2004. 
[44] Heylighen, A., Neuckermans, H., DYNAMO: A Dynamic Architectural Memory On-line, Educational Technology and Society 3(2), 86-95, 2000.

[45] Martin, W.M., Heylighen, A., Cavallin, H., Building ${ }^{2}$ stories - a hermeneutic approach to studying design practice, In: Proceedings of the 5th European Academy of Design Conference, 2003.

[46] Heylighen, A., Martin, W.M., Cavallin, H., From repository to resource: Exchanging stories of and for architectural practice, Journal of Design Research 4(1), 2004.

[47] Martin, W.M., Heylighen, A., Cavallin, H., The right story at the right time: towards a tacit knowledge resource for (student) designers, Al \& Society 19(1), 34-47, 2005.

[48] Heylighen, A., Martin, W.M., Cavallin, H., Accidental resource: A fable of design research through storytelling, In: International Workshop on Understanding Designers, 343-349, 2005.

[49] Martin, W.M., Heylighen, A., Cavallin, H., Knowledge sharing in the wild: Building Stories' attempt to unlock the knowledge capital of architectural practice, In: (Eds. S. Emmitt \& M. Prins) Proceedings of CIB W096 Architectural Management, 'Special Meeting' on Designing Value: New Directions in Architectural Management, 417-424, 2005.

[50] Martin, W.M., Heylighen, A., Cavallin, H., Building Stories revisited: Unlocking the knowledge capital of architectural practice, Architectural Engineering and Design Management 3(1), 65-74, 2007.

[51] Stefaner, M., Vecchia, E.D., Condotta, M., Wolpers, M., Specht, M., Apelt, S., Duval, E., MACE Enriching architectural learning objects for experience multiplication, In: Proceedings of the 2 nd European Conference on Technology Enhanced Learning, 322-336, 2007.

[52] Gradmann, S., Knowledge = Information in Context: on the Importance of Semantic Contextualisation in Europeana, Europeana White Paper, 2010, http://version1.europeana.eu/web/europeanaproject/whitepapers/ (last accessed on 3rd January 2011).

[53] Berners-Lee, T., Hendler, J., Lassila, O., The Semantic Web - A new form of Web content that is meaningful to computers will unleash a revolution of new possibilities, Scientific American 284(5), 3443, 2001.

[54] Pauwels, P., Architectural Information Modelling: a semantic description framework for historical and theoretical knowledge in architecture, In: Proceedings of the 15th Joint Doctoral Seminar in Theory and History of Architecture, 2008.

[55] Pauwels, P., Verstraeten, R., Jonckheere, T., De Meyer, R., Van Campenhout, J., 3D architectural design in the semantic web, In: Proceedings of the 7th Extended Semantic Web Conference, 2010.

[56] Pauwels, P., De Meyer, R., Van Campenhout, J., Interoperability for the design and construction industry through semantic web technology, In: Proceedings of the 5th International Conference on Semantic and Digital Media Technologies, 2010.

[57]Manola, F., Miller, E., RDF Primer - W3C Recommendation 10 February 2004, http://www.w3.org/TR/rdf-primer/ (last accessed on 3rd January 2011).

[58]Bizer, C., Heath, T., Berners-Lee, T., Linked Data - The Story So Far, International Journal on Semantic Web and Information Systems 5(3), 1-22, 2009.

[59] Cyganiak, R., The Linking Open Data cloud diagram, http://richard.cyganiak.de/2007/10/lod/ (last accessed on 3rd January 2011).

[60] GeoNames, http://www.geonames.org/ (last accessed on 3rd January 2011).

[61]Zhang, X., Hu, C., Li, H., Semantic query on materials data based on mapping MATML to an OWL ontology, Data Science Journal 8, 1-17, 2009.

[62] Brickley, D., Miller, L., FOAF Vocabulary Specification 0.98 - Namespace Document 9 August 2010 Marco Polo Edition, http://xmlns.com/foaf/spec/ (last accessed on 3rd January 2011).

[63]Becker, C., Bizer, C., flickr ${ }^{\mathrm{TM}}$ wrappr - Precise photo association, http://www4.wiwiss.fuberlin.de/flickrwrappr/ (last accessed on 3rd January 2011).

[64]DBpedia - About, http://dbpedia.org/ (last accessed on 3rd January 2011). 